\title{
Predicting the effects of $8 \mathrm{C} 2$, a monoclonal anti-topotecan antibody, on plasma and tissue disposition of topotecan
}

\author{
Dhaval K. Shah and Joseph P. Balthasar \\ Department of Pharmaceutical Sciences, University at Buffalo, The State University of New York, \\ Buffalo, NY 14260
}

\begin{abstract}
We are investigating an inverse targeting strategy to reduce the dose limiting systemic toxicities resultant from intraperitoneal (IP) administration of topotecan, a model chemotherapeutic drug. This approach utilizes systemic co-administration of anti-topotecan antibodies to alter the plasma and tissue disposition kinetics of topotecan. To better predict the effects of $8 \mathrm{C} 2$, a high affinity anti-topotecan monoclonal antibody, on the pharmacokinetics of topotecan, two mathematical models have been developed and evaluated. Model 1 is a hybrid physiologically based pharmacokinetic (PBPK) model that was created by merging a PBPK model for topotecan with a simple two compartment model of $8 \mathrm{C} 2$ pharmacokinetics. Model 2 is a comprehensive PBPK model developed by merging a PBPK model for IgG with a PBPK model for topotecan. To help validate the simulation results from both the models, a tissue distribution experiment was conducted, in which topotecan and 8C2 were co-administered in mice. Experimental and simulated data were compared by calculating the median percent prediction error (\%PE) for all tissues. For both models, the median \%PE values for all the tissues were less than $100 \%$, indicating that the predicted values were, on average, less than two-fold the observed plasma and tissue topotecan concentrations values. In general model 2 was found to be more predictive of the data set than model 1 , as the overall median $\% \mathrm{PE}$ value for model $2(\% \mathrm{PE}=63)$ was less than model $1(\% \mathrm{PE}=73)$.
\end{abstract}

\section{Keywords}

PBPK model; Monoclonal antibody; Topotecan; 8C2; Intraperitoneal chemotherapy; Inverse targeting; Mathematical modeling

\section{INTRODUCTION}

To alleviate the dose limiting systemic toxicity of intraperitoneally (IP) administered chemotherapeutic drugs, we have proposed an inverse targeting strategy, which attempts to decrease drug exposure to the sites associated with drug toxicities [1-3]. This strategy utilizes systemically administered anti-drug antibodies to reduce the systemic unbound drug exposure and the extravascular distribution of the chemotherapeutic drug. Previously, we have evaluated the inverse targeting hypothesis in a series of preclinical studies that employed methotrexate and anti-methotrexate antibodies [2-5]. In this prior work, the effects of anti-methotrexate antibodies on methotrexate toxicity were found to be protocoldependent, where, following different dosing protocols, co-administration of antimethotrexate antibodies led to increased, as well as decreased, methotrexate-induced

Corresponding author: Joseph P. Balthasar, Ph.D., Department of Pharmaceutical Sciences, 457B Cooke Hall, University at Buffalo, The State University of New York, Buffalo, New York 14260, Telephone: 716-645-4807, Fax: 716-645-3693, jb@acsu.buffalo.edu. 
toxicity [5]. These observations are not unique, as several examples appear in the literature that show that antibodies directed against drugs, toxins, or endogenous substances (e.g., cytokines) occasionally demonstrate unexpected agonist-like activity, increasing the magnitude of effects produced by their ligand [6-9]. Thus, the effects of anti-drug antibodies have been difficult to predict, both in terms of the direction of effect (agonistic vs. antagonistic) as well as in terms of magnitude of the effect. It is anticipated that the development of mechanistic mathematical models, incorporating major determinants of the kinetics of antibody-drug association, dissociation, distribution, elimination, and pharmacodynamics, may allow an improved prediction of the effects of anti-drug antibodies on drug disposition and on drug effects.

Presently, we are investigating the application of the inverse targeting strategy to enhance the pharmacokinetic selectivity of IP topotecan chemotherapy [10-13]. Topotecan, a chemotherapeutic agent of choice for the second-line treatment of refractory metastatic ovarian cancer, exhibits dose-dependent cytotoxicity $[12,14,15]$ where the dose-toxicity relationship is highly dependent on the topotecan administration protocol $[14,15]$. Although we hypothesize that anti-topotecan antibody administration will improve the selectivity of topotecan IP chemotherapy, it is difficult to identify, a priori, optimal dosing strategies of antibody and drug, due to the protocol dependencies associated with the inverse targeting approach and with the topotecan dose-toxicity relationship. In order to help evaluate the inverse targeting hypothesis for topotecan in silico, we have developed a physiologically based pharmacokinetic (PBPK) model to characterize the time-course of plasma and tissue topotecan exposure, following administration of different dosing levels in mice [16]. In the current work, the topotecan PBPK model has been merged with two competing models of $8 \mathrm{C} 2$ disposition to predict the effects of monoclonal anti-topotecan antibodies on the plasma and tissue disposition of topotecan.

The first model describes the pharmacokinetics of $8 \mathrm{C} 2$ with a simple, two compartment system, and the second describes $8 \mathrm{C} 2$ pharmacokinetics with a PBPK model. Each antibody pharmacokinetic model was merged with the topotecan PBPK model, and the interaction between topotecan and $8 \mathrm{C} 2$ was predicted through the use of microconstants describing the kinetics of binding association and dissociation. To evaluate the accuracy of model predictions, an in vivo investigation was conducted with Swiss Webster mice, and model predictions were compared to the experimental results.

\section{MATERIALS AND METHODS}

\section{Theoretical}

Development of Model 1: Topotecan PBPK model merged with mammillary model for 8C2-Schematic diagrams of the PBPK model used for topotecan, the twocompartment model used for $8 \mathrm{C} 2$, and the merged model are described in figures $1 \mathrm{~A}, 1 \mathrm{~B}$ and $1 \mathrm{C}$. The detailed description, equations and validation of the topotecan PBPK model (figure 1A) is described elsewhere [16]. Briefly, the model consists of 13 compartments (blood, lungs, heart, muscle, skin, spleen, gut, liver, kidney, brain, adipose, testes and IP fluid) connected to each other in an anatomical fashion via blood flow. Topotecan kinetics in the lungs, heart, muscle, skin, spleen, gut, liver, brain and adipose were described by simple perfusion rate-limited sub-models, whereas the testes and peritoneal fluid were described by a permeability rate-limited sub-models. Topotecan disposition in the kidney was described by a more complex permeability rate-limited model with a nonlinear efflux pathway. The testes and kidney were split into vascular and extravascular compartments. Enterohepatic circulation of topotecan was incorporated in the model with partial reabsorption from the gut lumen, and with nonlinear bioavailability. Topotecan follows dose-dependent nonlinear pharmacokinetics and its elimination was described by saturable elimination from the liver, 
and by parallel nonlinear and linear elimination from the kidney. The development and evaluation of the two-compartment model of $8 \mathrm{C} 2$ pharmacokinetics (figure 1B) has been described elsewhere [17]. Briefly, the model employs a classic two (systemic and peripheral) compartmental pharmacokinetic model to describe the systemic disposition of $8 \mathrm{C} 2$. After subcutaneous administration of $8 \mathrm{C} 2$, the antibody is absorbed into the central compartment via a first order rate process with dose-dependent bioavailability. The elimination of $8 \mathrm{C} 2$ from the central compartment is described by a linear clearance pathway and a parallel non-linear pathway to represent concentration-dependent FcRn saturation. During model development, the volume of the central compartment was fixed to the physiological plasma volume for mice. The portion of the merged model that describes the interaction between topotecan and $8 \mathrm{C} 2$ is shown in figure $1 \mathrm{C}$.

The amount of antibody present in subcutaneous compartment is described as $X A_{S C}$. From the subcutaneous site, the antibody is absorbed into the systemic circulation via the first absorption rate constant $K a$ with bioavailability $B A^{*}$, which is incorporated as:

$\mathrm{BA}^{*}=\mathrm{SCBA} \bullet\left(1-\frac{\text { Dose }}{\mathrm{KF}+\text { Dose }}\right) . S C B A$ is the subcutaneous bioavailability of $8 \mathrm{C} 2$ at low antibody doses, Dose is the subcutaneous antibody dose and $K F$ is a bioavailability constant. The concentration of $8 \mathrm{C} 2$ in central and peripheral compartments is displayed as $A 1$ and $A 2$. The volumes of the central and peripheral compartments for $8 \mathrm{C} 2$ are VAl (equal to plasma volume) and $V A 2$. The antibody is allowed to distribute between the central and peripheral compartment via the distribution clearance, CLDA. The elimination of $8 \mathrm{C} 2$ from central compartment is described as $C L A^{*}$, which is modeled as a function of the concentration of

$8 \mathrm{C} 2$ in the central compartment: $\mathrm{CLA}^{*}=\mathrm{CL}+\mathrm{ECL} \bullet\left(\frac{\mathrm{A} 1}{\mathrm{KCL}+\mathrm{A} 1}\right)$. $C L$ refers to the clearance of $8 \mathrm{C} 2$ at low concentrations, $E C L$ is the maximum value of clearance of antibodies in the absence of FcRn, and $K C L$ is a clearance constant. Topotecan concentrations in the blood compartment and in the peripheral compartment of the $8 \mathrm{C} 2$ disposition model are represented by: $L$. Antibodies in central and peripheral compartment are allowed to interact with topotecan via the association rate constant $K o n$ and dissociation rate constant Koff. The topotecan- $8 \mathrm{C} 2$ complex concentrations in central and peripheral compartment are described by $A L 1$ and $A L 2$. The antibody-topotecan complex is assumed to follow the same disposition kinetics as unbound $8 \mathrm{C} 2$. The elimination of topotecan- $8 \mathrm{C} 2$ complex from central compartment is described by $C L A^{*}$. Following elimination in complex with $8 \mathrm{C} 2$, topotecan is returned to the systemic circulation (i.e., returned to the blood compartment of the topotecan PBPK model). Equations describing the merged component of model 1 are described below.

$$
\begin{gathered}
\frac{\mathrm{dA} 1}{\mathrm{dt}}=-\mathrm{CLDA} \bullet \frac{\mathrm{A} 1}{\mathrm{VA} 1}+\mathrm{CLDA} \bullet \frac{\mathrm{A} 2}{\mathrm{VA} 1}-\mathrm{CLA}^{*} \bullet \frac{\mathrm{A} 1}{\mathrm{VA} 1}-\mathrm{Kon} \bullet \mathrm{A} 1 \bullet \mathrm{L}+\mathrm{Koff} \bullet \mathrm{AL} 1 \\
\frac{\mathrm{dA} 2}{\mathrm{dt}}=\mathrm{CLDA} \bullet \frac{\mathrm{A} 1}{\mathrm{VA} 2}-\mathrm{CLDA} \bullet \frac{\mathrm{A} 2}{\mathrm{VA} 2}-\mathrm{Kon} \bullet \mathrm{A} 2 \bullet \mathrm{L}+\mathrm{Koff} \bullet \mathrm{AL} 2 \\
\frac{\mathrm{dAL} 1}{\mathrm{dt}}=-\mathrm{CLDA} \bullet \frac{\mathrm{AL} 1}{\mathrm{VA} 1}+\mathrm{CLDA} \bullet \frac{\mathrm{AL} 2}{\mathrm{VA} 1}-\mathrm{CLA}^{*} \bullet \frac{\mathrm{AL} 1}{\mathrm{VA} 1}+\mathrm{Kon} \bullet \mathrm{A} 1 \bullet \mathrm{L}-\mathrm{Koff} \bullet \mathrm{AL} 1 \\
\frac{\mathrm{dAL} 2}{\mathrm{dt}}=\mathrm{CLDA} \bullet \frac{\mathrm{AL} 1}{\mathrm{VA} 2}-\mathrm{CLDA} \bullet \frac{\mathrm{AL} 2}{\mathrm{VA} 2}+\mathrm{Kon} \bullet \mathrm{A} 2 \bullet \mathrm{L}-\mathrm{Koff} \bullet \mathrm{AL} 2
\end{gathered}
$$




$$
\begin{aligned}
\mathrm{V}_{\mathrm{Blood}} & \bullet \frac{\mathrm{dL}}{\mathrm{dt}} \\
& =-\mathrm{Kon} \bullet \mathrm{A} 1 \bullet \mathrm{L} \bullet \mathrm{VA} 1 \\
& +\mathrm{Koff} \bullet \mathrm{AL} 1 \bullet \mathrm{VA} 1 \\
& -\mathrm{Kon} \bullet \mathrm{A} 2 \bullet \mathrm{L} \bullet \mathrm{VA} 2 \\
& +\mathrm{Koff} \bullet \mathrm{AL} 2 \bullet \mathrm{VA} 2 \\
& +\mathrm{CLA} \cdot \bullet \mathrm{AL} 1 \\
& -\left(\mathrm{Q}_{\mathrm{He}}+\mathrm{Q}_{\mathrm{Ki}}+\mathrm{Q}_{\mathrm{Li}}+\mathrm{Q}_{\mathrm{Te}}+\mathrm{Q}_{\mathrm{Mu}}+\mathrm{Q}_{\mathrm{Sk}}+\mathrm{Q}_{\mathrm{Br}}\right) \bullet \mathrm{L} \\
& +\mathrm{Q}_{\mathrm{He}} \bullet \mathrm{C}_{\mathrm{u}-\mathrm{He}} \\
& +\mathrm{Q}_{\mathrm{Ki}} \bullet \mathrm{C}_{\mathrm{u}-\mathrm{Ki}} \\
& +\mathrm{Q}_{\mathrm{Li}} \bullet \mathrm{C}_{\mathrm{u}-\mathrm{Li}} \\
& +\mathrm{Q}_{\mathrm{Te}} \bullet \mathrm{C}_{\mathrm{u}-\mathrm{Te}} \\
& +\mathrm{Q}_{\mathrm{Mu}} \bullet \mathrm{C}_{\mathrm{u}-\mathrm{Mu}} \\
& +\mathrm{Q}_{\mathrm{Sk}} \bullet \mathrm{C}_{\mathrm{u}-\mathrm{Sk}} \\
& +\mathrm{Q}_{\mathrm{Ad}} \bullet \mathrm{C}_{\mathrm{u}-\mathrm{Ad}} \\
& +\mathrm{Q}_{\mathrm{Br}} \bullet \mathrm{C}_{\mathrm{u}-\mathrm{Br}} \\
& -\mathrm{CLDIP} \bullet\left(\mathrm{L}-\mathrm{C}_{\mathrm{IP}}\right)+\frac{\mathrm{X}_{\mathrm{GL}}}{\mathrm{T}_{\mathrm{EHC}}} \bullet\left(\frac{\mathrm{X}_{\mathrm{GL}}}{\mathrm{K}_{\mathrm{BA}}+\mathrm{X}_{\mathrm{GL}}}\right)
\end{aligned}
$$

Equation 5 links the topotecan-8C2 interaction submodel to the topotecan PBPK model. $V_{B l o o d}$ refers to the volume of blood used for the topotecan PBPK model. $Q_{H e}, Q_{K i}, Q_{L i}$, $Q_{T e}, Q_{M w}, Q_{S k}, Q_{A d}$ and $Q_{B r}$ represent blood flow to the heart, kidney, liver, testes, muscle, skin, adipose and brain, respectively. $C_{u_{-} H e}, C_{u_{-} K i}, C_{u_{-} L i}, C_{u_{-} T e}, C_{u_{-} M w}, C_{u_{-} S k}, C_{u_{-} A d}$ and $C_{u_{-} B r}$ represent unbound concentration in effluent blood from the heart, kidney, liver, testes, muscle, skin, adipose and brain. $C L D I P$ is the distribution clearance of topotecan between blood and peritoneal compartment and $C_{I P}$ is the topotecan concentration in peritoneal compartment. $X_{G L}$ is the amount of drug in gut lumen compartment and $T_{E H C}$ is the transit time for the topotecan in gall bladder and gut lumen compartments. $K_{B A}$ is a bioavailability constant that characterizes the nonlinear bioavailability of topotecan from gut lumen compartment.

\section{Development of Model 2: Merging PBPK models for topotecan and IgG-In}

prior work, PBPK models have been developed for topotecan [16] and for immune gamma globulin (IgG) antibodies [18,19]. Model 2 represents a comprehensive physiologicallybased interaction model, which was created by merging the two prior PBPK models. The basic structure of the topotecan model is retained (figure 1A); however, each compartment (except blood and peritoneal fluid) was divided into 4 sub-compartments to represent the vascular space (V), endothelial space (E), interstitial space (IS) and cellular space (C). Figure $2 \mathrm{~A}$ presents a schematic diagram of the basic structure used for non-eliminating tissues. Drug enters and leaves the vascular compartment via blood flow $\left(Q_{T}\right)$. Drug distributes between the vascular and endothelial compartments, as well as between the endothelial and interstitial compartments, where the distributive clearance was arbitrarily set as 100 times the value of blood flow to the tissue. As such, distribution of topotecan between these spaces is modeled to be rapid, and perfusion-rate limited. The structure was modified for the testes and kidneys, which display permeability-rate limited topotecan distribution [16], and the model structure was further modified to account for nonlinear tissue binding in the gut and kidney (which were not considered in previous topotecan 
PBPK model) [16]. The concentration of drug in the cellular compartment was assumed to be in direct equilibrium with the concentration in the interstitial compartment, and the tissue to plasma partition coefficients $(K p)$ observed experimentally [16] were used as the proportionality constants. The model assumes that topotecan elimination occurs from the vascular space in the kidney and from the interstitial space in the liver. Topotecan tissue concentrations for a typical tissue was described as:

$\mathrm{C}_{\mathrm{T}}=\frac{\mathrm{C}_{\mathrm{V}} \bullet \mathrm{V}_{\mathrm{V}} \text { âńdC } \mathrm{E}_{\mathrm{E}} \bullet \mathrm{V}_{\mathrm{E}} \text { âńđC } \mathrm{IS} \bullet \mathrm{V}_{\mathrm{IS}} \text { âñdC } \mathrm{IS} \bullet \mathrm{Kp} \bullet \mathrm{V}_{\mathrm{C}}}{\mathrm{V}_{\mathrm{V}}+\mathrm{V}_{\mathrm{E}}+\mathrm{V}_{\mathrm{IS}}+\mathrm{V}_{\mathrm{C}}} \cdot C_{V}, C_{E}, C_{I S}$ and $C_{T}$ refer to concentrations of drug in vascular space, endothelial space, interstitial space and tissue homogenate. $V_{V}, V_{E}, V_{I S}$ and $V_{C}$ refer to the volumes of the vascular, endothelial, interstitial and cellular spaces. The modified topotecan PBPK model was simultaneously fitted to experimental data obtained from 1, 5, 10 and $30 \mathrm{mg} / \mathrm{kg}$ IV administration of topotecan in mice, and the estimated parameters were then used for model simulations.

The general structure of the PBPK model for $\mathrm{IgG}$, which is shown in figure $2 \mathrm{~B}$, has been presented previously [18,19]. The model consists of 9 compartments (plasma, heart, lung, liver, spleen, muscle, skin, gut and kidneys) connected to each other in an anatomical manner. Note that the present model does not include a tumor compartment, which was incorporated within the prior model. Each tissue compartment is divided into three subcompartments to represent the vascular, endothelial, and interstitial spaces. Figure $2 \mathrm{C}$ presents a schematic representation of the sub-compartment structure. The model incorporates key features related to antibody distribution and elimination, such as: (a) plasma circulation through organs and tissues, (b) uptake of antibody molecules from the vascular and interstitial compartment into the endothelial compartment via linear, fluid phase endocytosis, (c) capacity-limited binding of IgG to FcRn in the endothelial compartment of each tissue, (d) salvage of antibody molecules by recycling of the FcRnbound IgG to the vascular and interstitial compartments, (e) catabolic elimination of the unbound IgG from all compartments, (f) convective transport of IgG from vascular to the tissue interstitial space via transport through the paracellular pores in the vascular endothelium, and $(\mathrm{g})$ return of IgG from the tissue interstitial space to the systemic circulation via the lymph $[18,19]$.

After combined administration of topotecan (IP) and 8C2 (IV), as in our inverse targeting strategy, binding association and dissociation may occur in any tissue sub-compartment where the two molecules coexist. In the merged PBPK model, this interaction may occur in the vascular spaces, endothelial spaces, and the interstitial spaces of each tissue. Of note, the model assumes that $8 \mathrm{C} 2$ is unable to access the cellular spaces of the tissues and, consequently, topotecan in cellular spaces is modeled to be unavailable for binding to 8C2. The model employs microconstants of binding association (Kon) and dissociation (Koff), which were obtained via surface plasmon resonance analyses [17]. The model also assumes that there is a 1:1 binding between $8 \mathrm{C} 2$ and topotecan. The binding of topotecan to $8 \mathrm{C} 2$ is assumed to have no impact on the disposition of the antibody; thus, the disposition of the $8 \mathrm{C} 2$-topotecan complex is modeled in an identical manner to unbound 8C2. Figure 2D presents a schematic representation of a typical organ compartment used to describe the disposition of the 8C2-topotecan complex.

Representative mass balance equations for the vascular, endothelial, and interstitial subcompartments of a typical organ are described below.

Vascular space: 


$$
\begin{aligned}
\mathrm{V}_{\text {Organ }}^{\mathrm{V}} & \frac{\mathrm{d} \mathrm{C}_{\text {Organ }}^{\mathrm{V}}}{\mathrm{dt}} \\
= & \left(\mathrm{Q}_{\text {Organ }} \bullet \mathrm{C}_{\text {Plasma }}\right) \\
+ & (\mathrm{FR} \bullet \mathrm{R} 1 \bullet(1 \\
& \left.\left.\quad-\mathrm{fu}_{\text {Organ }}\right) \bullet \mathrm{V}_{\text {Organ }}^{\mathrm{E}} \bullet \mathrm{C}_{\text {Endo, Organ }}^{\text {Total }}\right) \\
- & \left(\mathrm{R} 1 \bullet \mathrm{C}_{\text {Organ }}^{\mathrm{V}} \bullet \mathrm{V}_{\text {Organ }}^{\mathrm{V}}\right) \\
- & \left(\left(1-\sigma_{\text {Organ }}^{\mathrm{V}}\right) \bullet \mathrm{L}_{\text {Organ }} \bullet \mathrm{C}_{\text {Organ }}^{\mathrm{V}}\right) \\
- & \left(\left(\mathrm{Q}_{\text {Organ }}\right.\right. \\
& \left.\left.-\mathrm{L}_{\text {Organ }}\right) \bullet \mathrm{C}_{\text {Organ }}^{\mathrm{V}}\right) \\
+ & \left(\mathrm{Kon}_{\mathrm{T}} \bullet \mathrm{TPT}_{\text {Organ }}^{\mathrm{V}} \bullet 8 \mathrm{C} 2_{\text {Organ }}^{\mathrm{V}}\right)-\left(\text { Koff } \bullet \mathrm{C}_{\text {Organ }}^{\mathrm{V}}\right)
\end{aligned}
$$

Endothelial space:

$$
\begin{aligned}
\mathrm{V}_{\text {Organ }}^{\mathrm{E}} & \frac{\mathrm{d} \mathrm{C}_{\text {Organ }}^{\mathrm{E}}}{\mathrm{dt}} \\
= & \left(\mathrm{R} 1 \bullet \mathrm{C}_{\text {Organ }}^{\mathrm{V}} \bullet \mathrm{V}_{\text {Organ }}^{\mathrm{V}}\right) \\
& -\left(\mathrm{fu}_{\text {Organ }} \bullet \mathrm{CL}_{\text {Organ }} \bullet \mathrm{C}_{\text {Endo, Organ }}^{\text {Total }}\right) \\
& -((1 \\
& \left.\left.-\mathrm{fu}_{\text {Organ }}\right) \bullet \mathrm{R} 1 \bullet \mathrm{V}_{\text {Organ }}^{\mathrm{E}} \bullet \mathrm{C}_{\text {Endo, Organ }}^{\text {Total }}\right) \\
+ & \left(\mathrm{R} 1 \bullet \mathrm{V}_{\text {Organ }}^{\mathrm{I}} \bullet \mathrm{C}_{\text {Organ }}^{\mathrm{I}}\right) \\
+ & \left(\mathrm{Kon} \bullet \mathrm{TPT}_{\text {Organ }}^{\mathrm{E}} \bullet 8 \mathrm{C} 2_{\text {Organ }}^{\mathrm{E}}\right)-\left(\text { Koff } \bullet \mathrm{C}_{\text {Organ }}^{\mathrm{E}}\right)
\end{aligned}
$$

Interstitial space:

$$
\begin{aligned}
\mathrm{V}_{\text {Organ }}^{\mathrm{I}} & \frac{\mathrm{d} \mathrm{C}_{\text {Organ }}^{\mathrm{I}}}{\mathrm{dt}} \\
= & ((1 \\
& \left.\left.\quad-\sigma_{\text {Organ }}^{\mathrm{V}}\right) \bullet \mathrm{L}_{\text {Organ }} \bullet \mathrm{C}_{\text {Organ }}^{\mathrm{V}}\right) \\
+ & ((1 \\
- & \mathrm{FR}) \bullet \mathrm{R} 1 \bullet(1 \\
- & \mathrm{fu} \text { Organ } \\
& \left.\left.\quad-\sigma_{\text {Organ }}^{\mathrm{I}}\right) \bullet \mathrm{V}_{\text {Organ }}^{\mathrm{E}} \bullet \mathrm{C}_{\text {Endo, Organ }}^{\text {Total }}\right)-((1 \\
- & \left(\mathrm{R} 1 \bullet \mathrm{V}_{\text {Organ }}^{\mathrm{I}} \bullet \mathrm{C}_{\text {Organ }}^{\mathrm{I}}\right) \\
+ & \left(\mathrm{Kon} \bullet \mathrm{TPT}_{\text {Organ }}^{\mathrm{I}} \bullet 8 \mathrm{C} 2_{\text {Organ }}^{\mathrm{I}}\right)-\left(\text { Koff } \bullet \mathrm{C}_{\text {Organ }}^{\mathrm{I}}\right)
\end{aligned}
$$

In the above equations $Q_{\text {Organ }}$ refers to the rate of plasma flow, and $V_{\text {Organ }}^{V}, V_{\text {Organ }}^{E}$ and $V_{\text {Organ }}^{I}$ refer to the volumes of vascular space, endothelial space and interstitial space for a given organ. $C_{\text {plasma }}$ refers to the $8 \mathrm{C} 2$-topotecan complex concentration in the plasma. $C_{\text {Organ }}^{V}, C_{\text {Organ }}^{E}$ and $C_{\text {Organ }}^{I}$ refer to the 8C2-topotecan complex concentrations in the vascular 
space, endothelial space and interstitial space. $T P T_{\text {Organ }}^{V}, T P T_{\text {Organ }}^{E}$ and $T P T_{\text {Organ }}^{I}$ refer to free topotecan concentrations in the vascular, endothelial and interstitial spaces of the organ. $8 C 2_{\text {Organ }}^{V}, 8 C 2_{\text {Organ }}^{E}$ and $8 C 2_{\text {Organ }}^{I}$ refer to free $8 \mathrm{C} 2$ concentrations in the vascular, endothelial and interstitial spaces of the organ. $C_{E n d o, \text { Organ }}^{\text {Total }}$ refers to the total antibody concentration (endogenous IgG $+8 \mathrm{C} 2+8 \mathrm{C} 2$-topoetcan complex) present in the endothelial space of the organ. $C L_{\text {organ }}$ denotes the clearance of the free (not bound to FcRn) 8C2-topotecan complex from the endothelial layer of the organ. $F R$ is the recycling fraction of FcRn bound $8 \mathrm{C} 2$-topotecan complex and $R l$ is the endothelial uptake and return rate of $8 \mathrm{C} 2$-topotecan complex. $\sigma_{\text {Organ }}^{V}$ and $\sigma_{\text {Organ }}^{I}$ represent the vascular and lymphatic reflection coefficients of $8 \mathrm{C} 2$ (and the 8C2-topotecan complex). The symbol $L_{\text {Organ }}$ describes lymph flow rate for the given organ, and fu is the unbound fraction of $\mathrm{IgG}$ in the endothelial space, which is incorporated as:

$$
\mathrm{fu}_{\text {Organ }}=\left(1-\frac{\left[\mathrm{A}-\sqrt{(\mathrm{A})^{2}-4 \bullet \mathrm{C}_{\text {Endo, organ }}^{\text {Total }} \bullet \mathrm{nPt}_{\text {organ }}}\right]}{2 \bullet \mathrm{C}_{\text {Endo, Organ }}^{\text {Total }}}\right)
$$

In the above equation, $\mathrm{A}=\left(\mathrm{Kd}_{\text {Organ }}+\mathrm{nPt}_{\text {Organ }}+\mathrm{C}_{\text {Endo, organ }}^{\text {Total }}\right) . n P t_{\text {Organ }}$ is the total FcRn concentration in the given tissue, and $K d_{\text {Organ }}$ is the dissociation constant for binding between FcRn and IgG. Of note, endogenous IgG, 8C2, and 8C2-topotecan complexes are assumed to demonstrate identical affinity for FcRn and, consequently, the three antibody species are pooled together for the determination of the bound and unbound fractions of $\operatorname{IgG}$ in the endothelial compartments.

\section{Mathematical Simulations}

Simulation of the inverse targeting experiment using Model 1-An inverse targeting experiment with IP administration of $1 \mathrm{mg} / \mathrm{kg}$ topotecan and simultaneous IV administration of a mole-equivalent dose of $8 \mathrm{C} 2(164 \mathrm{mg} / \mathrm{kg})$ was simulated using model 1 . Physiological and other parameter values for the topotecan PBPK model used as a part of model 1 have been presented previously [16]. Parameter values for the compartmental model used to describe disposition of $8 \mathrm{C} 2$ and $8 \mathrm{C} 2$-topotecan complex, as well as values of interaction parameters, are listed in Table 1 . In model 1, free topotecan concentrations in blood drive the tissue concentrations of topotecan. However, we recognize that, following administration of $8 \mathrm{C} 2$, the binding of topotecan to $8 \mathrm{C} 2$ will lead to very high blood concentrations of bound drug. To simulate the total concentrations of topotecan in tissue, it was deemed necessary to include consideration of the quantity of topotecan bound to $8 \mathrm{C} 2$ in the blood space in each organ. Hence, in our simulation output for model 1, we have incorporated the contributions of topotecan present in residual blood of each tissue. The residual blood volumes for each tissue are listed in Table 2 [20-22]. For each tissue (except blood and IP fluid), the observed concentration was simulated using the following equation:

$$
\mathrm{CT}_{\text {obs }}=\frac{\left(\mathrm{C}_{\mathrm{T}} \bullet \mathrm{V}_{\mathrm{T}}+\mathrm{C}_{\text {bound }} \bullet \mathrm{V}_{\mathrm{T}} \bullet \frac{\text { \%Residual }}{100}\right)}{\mathrm{V}_{\mathrm{T}}}
$$

$C T_{o b s}$ is the simulated tissue homogenate concentration for a given tissue. $C_{T}$ is the simulated tissue concentration of topotecan in a given tissue, which is based on free topotecan concentration in blood. $C_{\text {bound }}$ is the concentration of $8 \mathrm{C} 2$-topotecan complex present in blood. $V_{T}$ is the volume of a given tissue, and \%Residual is the percentage of 
tissue mass comprised of residual blood. Simulations were conducted using the SIM program and individual simulation option available in ADAPT 5 software (BMSR, University of Southern California).

Simulation of the inverse targeting experiment using Model 2-Similar to the description provided for simulations with model 1, an inverse targeting experiment with IP administration of $1 \mathrm{mg} / \mathrm{kg}$ topotecan and simultaneous IV administration of $164 \mathrm{mg} / \mathrm{kg} 8 \mathrm{C} 2$ was simulated using model 2. Parameter values used to characterize the modified topotecan PBPK model are shown in Table 3 . The values of parameters used to characterize the disposition of 8C2 or 8C2-topotecan complex were obtained from Urva et al. [19]. The values for the association rate constant (Kon) and dissociation rate constant (Koff) were obtained through SPR analysis and they were $9.271 / \mathrm{nM} / \mathrm{h}$ and $4.681 / \mathrm{h}$, respectively (please refer to Shah and Balthasar[17] for experimental details). The simulated topotecan concentration in a tissue homogenate was incorporated using the following equation:

$\mathrm{CT}_{\mathrm{OBS}}=\frac{\mathrm{TPT}_{\text {Organ }}^{\mathrm{V}} \bullet \mathrm{V}_{\mathrm{V}}+\mathrm{TPT}_{\text {Organ }}^{\mathrm{E}} \bullet \mathrm{V}_{\mathrm{E}}+\mathrm{TPT}_{\text {Organ }}^{\mathrm{I}} \bullet \mathrm{V}_{\mathrm{IS}}+\mathrm{TPT}_{\text {Organ }}^{\mathrm{I}} \bullet \mathrm{Kp} \bullet \mathrm{V}_{\mathrm{C}}+\mathrm{C}_{\text {Organ }}^{\mathrm{V}} \bullet \mathrm{V}_{\mathrm{V}}+\mathrm{C}_{\text {Organ }}^{\mathrm{E}} \bullet \mathrm{V}_{\mathrm{E}}+\mathrm{C}_{\text {Organ }}^{\mathrm{I}} \bullet \mathrm{V}_{\mathrm{IS}}}{\mathrm{V}_{\mathrm{V}}+\mathrm{V}_{\mathrm{E}}+\mathrm{V}_{\mathrm{IS}}+\mathrm{V}_{\mathrm{C}}}$

In this equation, $C T_{o b s}$ is the simulated tissue homogenate concentration of topotecan for a given tissue. $V_{V}, V_{E}, V_{I S}$ and $V_{C}$ refer to the volumes of vascular, endothelial, interstitial and cellular spaces. $T P T_{\text {Organ }}^{V}, T P T_{\text {Organ }}^{E}$ and $T P T_{\text {Organ }}^{I}$ refer to free topotecan concentrations in vascular, endothelial and interstitial spaces of the organ. $C_{\text {Organ }}^{V}, C_{\text {Organ }}^{E}$ and $C_{\text {Organ }}^{I}$ refer to the 8C2-topotecan complex concentrations in the vascular space, endothelial space and interstitial space of a given organ. Simulations for model 2 were conducted using the SIM program and individual simulation option available in ADAPT 5 software (BMSR, University of southern California).

Chemicals and animals - Topotecan, as the hydrochloride salt (SK\&F S-104864-A), was purchased from Beta Pharma Inc. (New Haven, CT). The high affinity anti-topotecan monoclonal antibody, 8C2, was generated from hybridoma cells, using our previously published protocol [13]. Triethylamine, acridine, potassium dihydrogenphosphate, phosphoric acid and methanol were purchased from Sigma (St. Louis, MO, USA). The water used for HPLC was double distilled water. All other chemicals were of analytical grade. Swiss Webster male mice (20-30 g, 4-5 weeks old, Harlan Laboratories, Inc., Indianapolis, IN) were used for the PBPK study. Protocols for animal use were approved by the Institutional Animal Care and Use Committee of the University at Buffalo. Mice were housed in a sterile room on a standard light-dark cycle, with continuous access to food and water.

Dosing, sampling and sample analysis-A group of 33 animals was injected simultaneously with $1 \mathrm{mg} / \mathrm{kg}$ of topotecan IP and with a mole-equivalent dose of $8 \mathrm{C} 2 \mathrm{IV}$ (i.e., $164 \mathrm{mg} / \mathrm{kg}$ ). After administration, three mice were sacrificed at each time point and samples were collected at 5, $30 \mathrm{~min}, 1$, 3, 6, 12h, 1, 5, 9, 16 and 23 days. From each animal, blood, lungs, heart, muscle, skin, spleen, gut, liver, kidney, brain, adipose, testes and IP fluid were collected. Plasma was obtained from blood following centrifugation at $10,000 \mathrm{~g}$ for 2 min. Samples of peritoneal fluid were collected with pre-weighed filter paper, and the volume of collected fluid was determined by weight, assuming the density of $1 \mathrm{~g} / \mathrm{mL}$. Plasma and all tissues were collected, weighed and stored at $-20^{\circ} \mathrm{C}$ until further analyzed by a validated reversed-phase HPLC assay previously developed in our lab [23]. This assay measures total topotecan concentration as the sum of lactone and carboxylate forms, and 
uses acridine as an internal standard. Tissue samples were prepared by homogenization into a known volume of saline with a Tissue Tearor ${ }^{\circledR}$ (Biospec Products, Bartlesville, OK; Model\#398, 985370-395).

Peritoneal fluid samples were prepared by homogenizing the filter paper containing peritoneal fluid into a known volume of $100 \mathrm{mM}$ phosphoric acid. For HPLC analysis, $20 \mu \mathrm{L}$ of samples were mixed with $2 \mu \mathrm{L}$ of internal standard, $56 \mu \mathrm{L}$ ice-cold methanol and $20 \mu \mathrm{L}$ $100 \mathrm{mM} \mathrm{H}_{3} \mathrm{PO}_{4}$ and vortexed for 10s. Samples were then centrifuged at 16,000 $\mathrm{g}$ for 10 minutes and the supernatant was injected within the HPLC system. The lower limit of quantification for topotecan was $1 \mathrm{ng} / \mathrm{mL}$, and recovery from tissue samples was more than 98\%. Within- and between-day CV\% were less than 13\%, and the assay was linear over a concentration range of $1-2000 \mathrm{ng} / \mathrm{mL}$ (i.e. $2.2-4376 \mathrm{nM}$ ).

Data Analysis-Noncompartmental analysis of the total plasma and tissue topotecan concentrations was performed using WinNonlin (V 5.0) software. For both models, the simulated plasma and tissue concentration data obtained after combined topotecan and $8 \mathrm{C} 2$ administration were compared to the observed data. For quantitative comparison of observed and simulated data, the median percent predictive error $\left(\% \mathrm{PE}=\frac{\left|\mathrm{C}_{\mathrm{Pred}}-\mathrm{C}_{\mathrm{Obs}}\right|}{\mathrm{C}_{\mathrm{Obs}}} \bullet 100\right)$ was calculated for plasma and each tissue. Here, $C_{\text {Pred }}$ is the predicted total concentrations of topotecan and $C_{O b s}$ is the observed total concentrations of topotecan.

\section{RESULTS}

Figure 3A shows the simulated tissue topotecan concentrations, generated using model 1, after simultaneous administration of $1 \mathrm{mg} / \mathrm{kg}$ topotecan IP and $164 \mathrm{mg} / \mathrm{kg}$ (equimolar) $\mathrm{mg} /$ $\mathrm{kg} 8 \mathrm{C} 2 \mathrm{IV}$. The figure shows two different profiles for each tissue, one with the tissue concentrations corrected by adding residual blood contents and one without correction. As clearly evident from the figure, the additional amount of topotecan present in residual blood dramatically changed the tissue concentrations. Figure 3B displays the ratio of AUCs calculated from the predicted concentration vs. time profiles, with or without consideration of the quantity of topotecan present in residual blood. The ratio varied considerably from tissue-to-tissue; the lowest ratio was found for the gut (6) and the highest ratio was observed for brain (1123).

Figure 4 shows the simulated total topotecan concentrations for tissue and plasma, generated using model 2 . The figure also compares the simulations from model 2 with the total topotecan concentrations simulated using model 1 and total topotecan concentrations generated after administration of $1 \mathrm{mg} / \mathrm{kg}$ topotecan in absence of $8 \mathrm{C} 2$. Topotecan concentrations dropped very quickly in absence of $8 \mathrm{C} 2$, and most of the drug was cleared from the body by $12 \mathrm{~h}$. Model 1 and 2 each predict that $8 \mathrm{C} 2$ will produce a dramatic increase in the cumulative exposure of total (i.e., bound + unbound) topotecan. The models predict that substantial topotecan concentrations will remain more than one month after administration.

In the subsequent evaluation experiment, where $1 \mathrm{mg} / \mathrm{kg}$ of topotecan was administered IP along with simultaneous administrations of $164 \mathrm{mg} / \mathrm{kg} \mathrm{mg} / \mathrm{kg} 8 \mathrm{C} 2 \mathrm{IV}$, samples were collected up to 23 days after dosing. Figure 5 and Figure 6 compare the model simulations with the observed plasma and tissue topotecan concentrations. It is important to emphasize that no model parameters have been estimated in this exercise, the plots provide a simple overlay of the predictions of model 1 and model 2 to the observed experimental data. As shown in figure 5, model 1 was able to capture the general behavior of the total topotecan (free topotecan + topotecan-8C2 complex) reasonably well. The terminal slope of decline in 
plasma total topotecan concentration was slightly higher in observed data compared to simulations. With the exception of the spleen, the model under-predicted topotecan concentrations in tissue. The median \% PE values for all tissues are listed in Table 4. The lowest median \%PE value for model 1 was for prediction of brain tissue concentrations (43) and the highest value was related to the prediction of skin concentrations (91).

Figure 6 compares the model simulations generated using model 2 with the observed plasma and tissue topotecan concentrations. As shown in the figure, model 2 was able to capture the trend for plasma and tissue concentrations quite well. There was an overall underestimation of plasma total topotecan concentrations compared to the observed values, but the median $\%$ PE was less than 100 (68\%). For many tissues, model 2 predicted the topotecan concentrations very well. The median \%PE values for model 2 are presented in Table 4 . The lowest median \%PE value was found for the spleen (34) and the highest value was for the skin (76).

\section{DISCUSSION}

For more than 100 years, antibody preparations have been evaluated for immunotoxicotherapy, where antibodies are applied to reduce the toxic effects associated with soluble substances, including toxins [24] (e.g., diphtheria toxin, mushroom toxins, snake [25] and spider venom [26]), drugs (e.g., digoxin [27], colchicine [28]), and endogenous substances (tissue necrosis factor alpha [29], vascular endothelial growth factor [30], etc.). This application of antibody therapy, which has been highly successful, achieves benefit largely through the ability of antibody to alter the distribution, elimination, and receptor binding of the target ligand. Although the main focus of immunotoxicotherapy has been to (simply) minimize the toxic effects associated with ligand exposure, there is some promise that anti-ligand antibodies may be applied to modulate the site-selectivity of ligand exposure and ligand effects. One such strategy, which is under development in this laboratory, combines intraperitoneal chemotherapy with intravenous anti-drug antibody therapy to increase the ratio of unbound drug exposure in the peritoneal cavity, relative to the unbound drug exposure in the systemic circulation. This approach, which may be categorized as an inverse targeting strategy, attempts to improve the safety and efficacy of intraperitoneal chemotherapy of peritoneal tumors (e.g., as found in ovarian cancer) by decreasing the delivery of drug to systemic tissues associated with drug toxicity.

Preliminary investigations regarding the inverse targeting strategy were carried out with methotrexate and anti-methotrexate antibodies $[1,2,4,5]$. Combined IP methotrexate therapy and IV anti-methotrexate antibody therapy was demonstrated to allow a substantial increase in the maximally tolerated dose of methotrexate, and also allow a significant improvement in animal survival in a mouse model of peritoneal cancer. Methotrexate was a valuable model drug, but this agent is not currently used in the treatment of human ovarian cancer. Subsequent work has been conducted with topotecan, which is the second-line agent of choice for recurrent ovarian cancer. In work conducted with mice actively immunized to induce anti-topotecan antibodies [10-12], it was demonstrated that the endogenous antitopotecan antibodies were able to reduce the systemic exposure to unbound topotecan, increase the tolerable dose, and improve animal survival in a peritoneal tumor model. Currently, we are investigating passive immunization with $8 \mathrm{C} 2$, a high-affinity antitopotecan antibody, for inverse targeting with IP topotecan chemotherapy.

To optimize protocol selection and targeting efficiency, we are interested using mathematical models to evaluate and characterize the factors responsible for the disposition and interaction of topotecan and $8 \mathrm{C} 2$. There have been very few prior publications of mathematical models to predict the effects of antibodies on the disposition of soluble 
ligands. In 1994 and 1996 Balthasar and Fung presented models to predict the effects of anti-digoxin antibodies on digoxin disposition and to predict the effects of anti-methotrexate antibodies on methotrexate pharmacokinetics [3,1]. In the later study, a mathematical model was applied to simulate the effects of systemic administration of anti-methotrexate $\operatorname{IgG}$ or Fab fragments on (a) total plasma methotrexate concentrations, (b) the maximal free concentration of methotrexate in plasma $\left(C_{\max f}\right)$, and (c) the systemic exposure to free methotrexate $\left(A U C_{f}\right)$. Subsequently, the same dosing protocols used in simulations were investigated in a rat model, and experimental results were compared to the model predictions. In general, the model predicted the effect of anti-methotrexate IgG or Fab on the systemic pharmacokinetics of methotrexate well. The model was then applied to assist in the design of optimum dosage protocols of anti-methotrexate $\operatorname{IgG}$ and Fab for minimizing methotrexate exposure and toxicity. More recently, Betts and coworkers [31] presented a target mediated drug disposition model to characterize and predict the effects of a humanized anti-Dickkopf-1 (Dkk-1) antibody on the systemic disposition of Dkk-1 in rats. The authors developed the Target Mediated Drug Disposition (TMDD) [32] model based on the available mechanistic information about the antibody and the target and simulated experimental plasma concentrations of the antibody and Dkk-1 after weekly intravenous administration to rats. Subsequently, they carried out pharmacokinetic studies using the same dosing protocols and compared the observed results with simulation. The model was able to capture Dkk-1 and antibody concentration versus time profiles. The authors further scaled up the model for prediction of effects in monkeys. The model provided excellent prediction of the monkey data. These examples, while few in number, clearly demonstrate the predictive utility of mathematical models for immunotoxicotherapy applications.

In this report we have described the development and validation of two mathematical models that have been designed to predict the effects of $8 \mathrm{C} 2$ on the plasma and tissue disposition of topotecan. Considering that the experimental animals had no exposure to topotecan prior to dosing, the models assumed an absence of endogenous anti-topotecan antibodies. Model 1 was developed by merging a PBPK model of topotecan with a simple, two compartment model developed for 8C2 (figure 1). The topotecan PBPK model, which was validated over wide dose range, was essential to characterize the complex nature of topotecan pharmacokinetics (e.g. nonlinear elimination and enterohepatic circulation) and to predict the tissue concentrations of topotecan after $8 \mathrm{C} 2$ administration. The compartmental model developed for $8 \mathrm{C} 2$ incorporated nonlinearities in $8 \mathrm{C} 2$ pharmacokinetics that are observed following the administration of large doses of this antibody. The model predicts dose dependant $8 \mathrm{C} 2$ bioavailability following SC dosing and nonlinear clearance from the central compartment. Both nonlinearities are presumably related to the saturation of $\mathrm{FcRn}$, which protects IgG antibodies from catabolism [33-36]. In model 1, the interaction between topotecan and 8C2 was incorporated in the plasma space of the topotecan PBPK model, which overlaps with the central and peripheral compartments of the $8 \mathrm{C} 2$ model. Tissue concentrations of topotecan are directly related to unbound topotecan concentrations in plasma. Model output incorporated a correction of tissue concentrations by inclusion of the estimated quantity of topotecan present in residual blood (within excised tissues). This correction is necessary because after equimolar administration of $8 \mathrm{C} 2$ and topotecan, most of the drug is expected to form complexes with the antibody, with high concentrations of the complex in plasma. Considering the low tissue to plasma partition coefficient of antibodies $[22,18]$, even minute amounts of residual blood in tissue samples may contribute considerably to the observed total topotecan concentrations in tissue after homogenation. Indeed, simulation results (figure 3A and 3B) showed that the incorporation of topotecan in residual blood dramatically increased tissue concentrations of topotecan. Tissue AUCs were 6 to 1123 times higher compared values predicted without inclusion of drug in residual blood. 
Model 2 represents the combination of PBPK models for topotecan and IgG (figure 3). The IgG PBPK model has been developed for prediction and characterization of the disposition of murine IgG1 monoclonal antibodies in mice $[18,19]$. The model incorporates many key features related to IgG tissue disposition, including binding to FcRn and recycling, degradation of unbound IgG, transport from blood to tissue interstitial fluid via convective transport and FcRn-mediated transcytosis, and return of IgG to blood via lymphatic transport. In order to merge the topotecan PBPK model with the PPBK model for IgG, the topotecan PBPK model required some modification. The original topotecan model[16] described many tissues, except testes and kidney, using perfusion-limited sub-models. However, to allow interaction of topotecan and $8 \mathrm{C} 2$ in tissues, all organs represented in the model were sub-divided in vascular, endothelial and interstitial spaces. Topotecan tissue concentrations in the cellular space were assumed to be directly proportional to the interstitial space topotecan concentrations, using $K p$ values as proportionality constants. The distribution clearance of topotecan between sub-compartments was fixed to a high value (100 times greater than the rate of tissue blood flow), to be consistent with the prior observation of apparent, perfusion-limited distribution.

As shown in figures 4 and 5, each model provided very good prediction of the complex interaction of topotecan and $8 \mathrm{C} 2$, and allowed good prediction of topotecan concentrations in plasma and in tissues. Clearly, model 1 is simpler than model 2; however, the overall median percentage prediction error for model 2 was $63 \%$ compared to $73 \%$ for model 1 , suggesting that model 2 is superior to model 1 . Nonetheless, both models performed quite well, given that no parameters were fitted within this exercise.

In summary, we have shown development and evaluation of two mathematical models that characterize the effect of $8 \mathrm{C} 2$ on topotecan plasma and tissue disposition. Model 1 was developed by merging a previously developed PBPK model of topotecan with a simple, two compartment model for $8 \mathrm{C} 2$ pharmacokinetics. Model 2 was developed by merging PBPK models for IgG and topotecan. Both models predicted plasma and tissue concentrations of topotecan reasonably well. The median \% PE values for both models were less than 100 . Overall, model 2 was perceived to be superior to model 1 , and this model will be evaluated in subsequent efforts to develop optimized dosing regimens of topotecan and $8 \mathrm{C} 2$.

\section{Acknowledgments}

This work was supported by the National Cancer Institute of the National Institutes of Health [CA118213 to J.B.], and by the Center for Protein Therapeutics at the University at Buffalo.

\section{REFERENCES}

1. Balthasar J, Fung HL. Utilization of antidrug antibody fragments for the optimization of intraperitoneal drug therapy: studies using digoxin as a model drug. J Pharmacol Exp Ther. 1994; 268(2):734-739. [PubMed: 8113985]

2. Balthasar JP, Fung HL. High-affinity rabbit antibodies directed against methotrexate: production, purification, characterization, and pharmacokinetics in the rat. J Pharm Sci. 1995; 84(1):2-6. [PubMed: 7714737]

3. Balthasar JP, Fung HL. Inverse targeting of peritoneal tumors: selective alteration of the disposition of methotrexate through the use of anti-methotrexate antibodies and antibody fragments. J Pharm Sci. 1996; 85(10):1035-1043. [PubMed: 8897267]

4. Lobo ED, Balthasar JP. Application of anti-methotrexate Fab fragments for the optimization of intraperitoneal methotrexate therapy in a murine model of peritoneal cancer. J Pharm Sci. 2005; 94(9):1957-1964. [PubMed: 16052545] 
5. Lobo ED, Soda DM, Balthasar JP. Application of pharmacokinetic-pharmacodynamic modeling to predict the kinetic and dynamic effects of anti-methotrexate antibodies in mice. J Pharm Sci. 2003; 92(8):1665-1676. [PubMed: 12884253]

6. Faulstich H, Kirchner K, Derenzini M. Strongly enhanced toxicity of the mushroom toxin alphaamanitin by an amatoxin-specific Fab or monoclonal antibody. Toxicon. 1988; 26(5):491-499. [PubMed: 3188055]

7. Fisher CJ Jr, Agosti JM, Opal SM, Lowry SF, Balk RA, Sadoff JC, Abraham E, Schein RM, Benjamin E. Treatment of septic shock with the tumor necrosis factor receptor:Fc fusion protein. The Soluble TNF Receptor Sepsis Study Group. N Engl J Med. 1996; 334(26):1697-1702. [PubMed: 8637514]

8. May LT, Neta R, Moldawer LL, Kenney JS, Patel K, Sehgal PB. Antibodies chaperone circulating IL-6. Paradoxical effects of anti-IL-6 "neutralizing" antibodies in vivo. J Immunol. 1993; 151(6): 3225-3236. [PubMed: 8376777]

9. Sato TA, Widmer MB, Finkelman FD, Madani H, Jacobs CA, Grabstein KH, Maliszewski CR. Recombinant soluble murine IL-4 receptor can inhibit or enhance IgE responses in vivo. J Immunol. 1993; 150(7):2717-2723. [PubMed: 8454851]

10. Chen, J. PhD Thesis. Department of Pharmaceutical Sciences, SUNY at Buffalo; 2005. Optimization of intraperitoneal topotecan chemotherapy with anti-topotecan antibodies. Chapter 6; p. 187-215.

11. Chen, J. PhD Thesis. Department of Pharmaceutical Sciences, SUNY at Buffalo; 2005. Optimization of intraperitoneal topotecan chemotherapy with anti-topotecan antibodies. Chapter 1; p. 1-45.

12. Chen, J. PhD Thesis. Department of Pharmaceutical Sciences, SUNY at Buffalo; 2005.

Optimization of intraperitoneal topotecan chemotherapy with anti-topotecan antibodies. Chapter 3; p. 81-123.

13. Chen, J.; Balthasar, JP. Handbook of pharmaceutical biotechnology. John Wiley and Sons, Hoboken, New Jersey; 2007. Development and characterization of high affinity anti-topotecan IgG and Fab fragments.

14. Herben VM, ten Bokkel Huinink WW, Beijnen JH. Clinical pharmacokinetics of topotecan. Clin Pharmacokinet. 1996; 31(2):85-102. [PubMed: 8853931]

15. Rowinsky EK, Verweij J. Review of phase I clinical studies with topotecan. Semin Oncol. 1997; 24 Suppl 20(6) S20-23-S20-10.

16. Shah DK, Balthasar JP. Physiologically based pharmacokinetic model for topotecan in mice. J Pharmacokinet Pharmacodyn. 2011; 38(1):121-142. [PubMed: 21104004]

17. Shah DK, Balthasar JP. Improving the safety of intraperitoneal topotecan chemotherapy using a high affinity anti-topotecan antibody: A pharmacokinetic/toxicodynamic model development and evaluation. Int J Pharm. 2011 (Manuscript in communication).

18. Garg A, Balthasar JP. Physiologically-based pharmacokinetic (PBPK) model to predict IgG tissue kinetics in wild-type and FcRn-knockout mice. J Pharmacokinet Pharmacodyn. 2007; 34(5):687709. [PubMed: 17636457]

19. Urva SR, Yang VC, Balthasar JP. Physiologically based pharmacokinetic model for T84.66: a monoclonal anti-CEA antibody. J Pharm Sci. 99(3):1582-1600. [PubMed: 19774657]

20. Bernareggi A, Rowland M. Physiologic modeling of cyclosporin kinetics in rat and man. J Pharmacokinet Biopharm. 1991; 19(1):21-50. [PubMed: 2023108]

21. Khor SP, Mayersohn M. Potential error in the measurement of tissue to blood distribution coefficients in physiological pharmacokinetic modeling. Residual tissue blood. I. Theoretical considerations. Drug Metab Dispos. 1991; 19(2):478-485. [PubMed: 1676658]

22. Garg, A. PhD Thesis. Department of Pharmaceutical Sciences, SUNY at Buffalo; 2007. Investigation of the role of FcRn in the absorption, distribution, and elimination of monoclonal antibodies. Chapter 3; p. 71-111.

23. Chen J, Balthasar JP. High-performance liquid chromatographic assay for the determination of total and free topotecan in the presence and absence of anti-topotecan antibodies in mouse plasma. J Chromatogr B Analyt Technol Biomed Life Sci. 2005; 816(1-2):183-192. 
24. Sullivan JB Jr. Past, present, and future immunotherapy of snake venom poisoning. Ann Emerg Med. 1987; 16(9):938-944. [PubMed: 3631680]

25. Seifert SA, Boyer LV. Recurrence phenomena after immunoglobulin therapy for snake envenomations: Part 1. Pharmacokinetics and pharmacodynamics of immunoglobulin antivenoms and related antibodies. Ann Emerg Med. 2001; 37(2):189-195. [PubMed: 11174238]

26. Heard K, O'Malley GF, Dart RC. Antivenom therapy in the Americas. Drugs. 1999; 58(1):5-15. [PubMed: 10439926]

27. Antman EM, Wenger TL, Butler VP Jr, Haber E, Smith TW. Treatment of 150 cases of lifethreatening digitalis intoxication with digoxin-specific Fab antibody fragments. Final report of a multicenter study. Circulation. 1990; 81(6):1744-1752. [PubMed: 2188752]

28. Putterman C, Ben-Chetrit E, Caraco Y, Levy M. Colchicine intoxication: clinical pharmacology, risk factors, features, and management. Semin Arthritis Rheum. 1991; 21(3):143-155. [PubMed: 1788551]

29. Saravolatz LD, Wherry JC, Spooner C, Markowitz N, Allred R, Remick D, Fournel M, Pennington JE. Clinical safety, tolerability, and pharmacokinetics of murine monoclonal antibody to human tumor necrosis factor-alpha. J Infect Dis. 1994; 169(1):214-217. [PubMed: 8277186]

30. Hasan J, Jayson GC. VEGF antagonists. Expert Opin Biol Ther. 2001; 1(4):703-718. [PubMed: 11727506]

31. Betts AM, Clark TH, Yang J, Treadway JL, Li M, Giovanelli MA, Abdiche Y, Stone DM, Paralkar VM. The application of target information and preclinical pharmacokinetic/pharmacodynamic modeling in predicting clinical doses of a Dickkopf-1 antibody for osteoporosis. J Pharmacol Exp Ther. 333(1):2-13. [PubMed: 20089807]

32. Mager DE, Jusko WJ. General pharmacokinetic model for drugs exhibiting target-mediated drug disposition. J Pharmacokinet Pharmacodyn. 2001; 28(6):507-532. [PubMed: 11999290]

33. Ghetie V, Ward ES. FcRn: the MHC class I-related receptor that is more than an IgG transporter. Immunol Today. 1997; 18(12):592-598. [PubMed: 9425738]

34. Ghetie V, Ward ES. Transcytosis and catabolism of antibody. Immunol Res. 2002; 25(2):97-113. [PubMed: 11999172]

35. Junghans RP. Finally! The Brambell receptor (FcRB). Mediator of transmission of immunity and protection from catabolism for IgG. Immunol Res. 1997; 16(1):29-57. [PubMed: 9048207]

36. Tabrizi MA, Tseng CM, Roskos LK. Elimination mechanisms of therapeutic monoclonal antibodies. Drug Discov Today. 2006; 11(1-2):81-88. [PubMed: 16478695] 
A

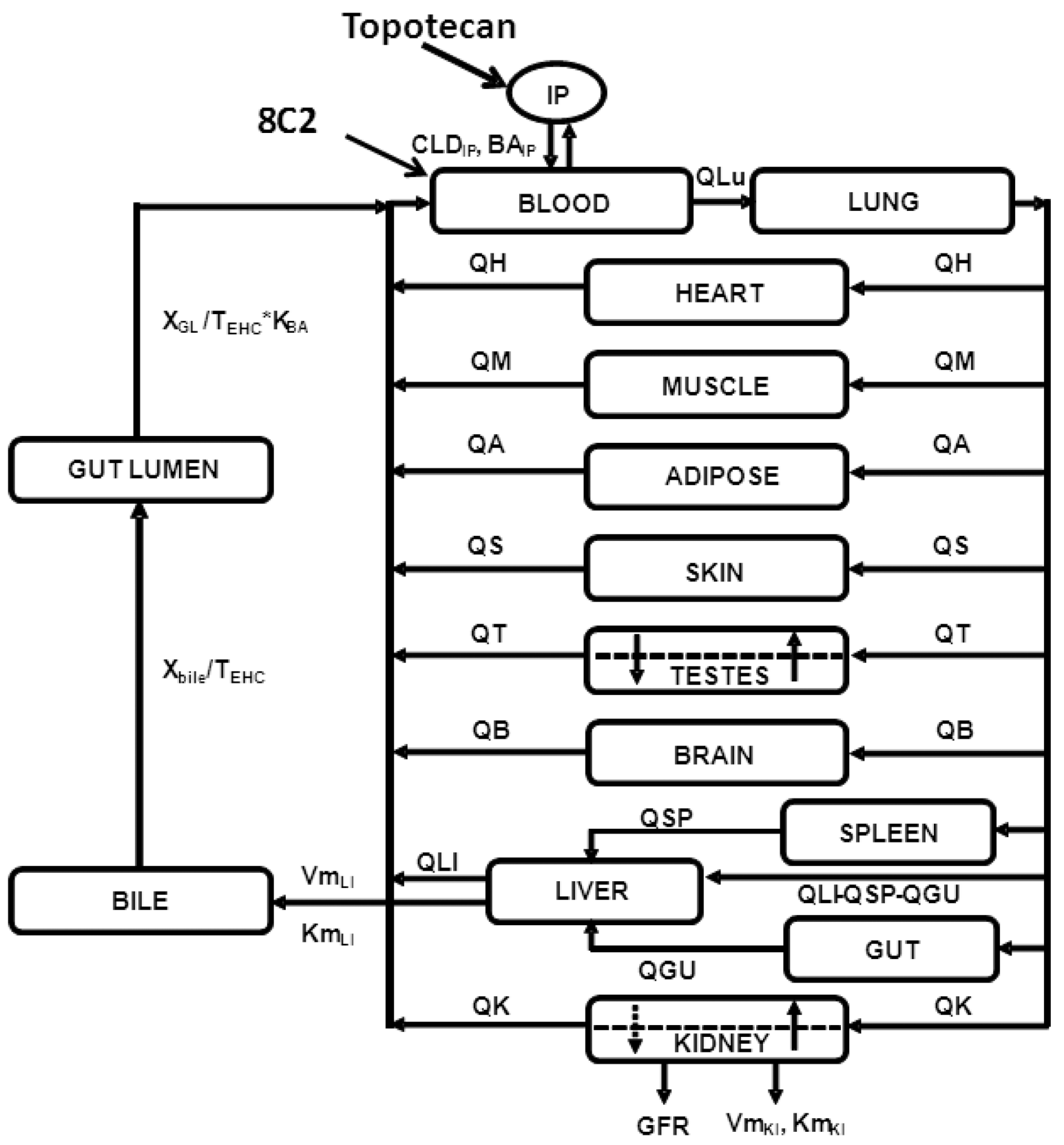



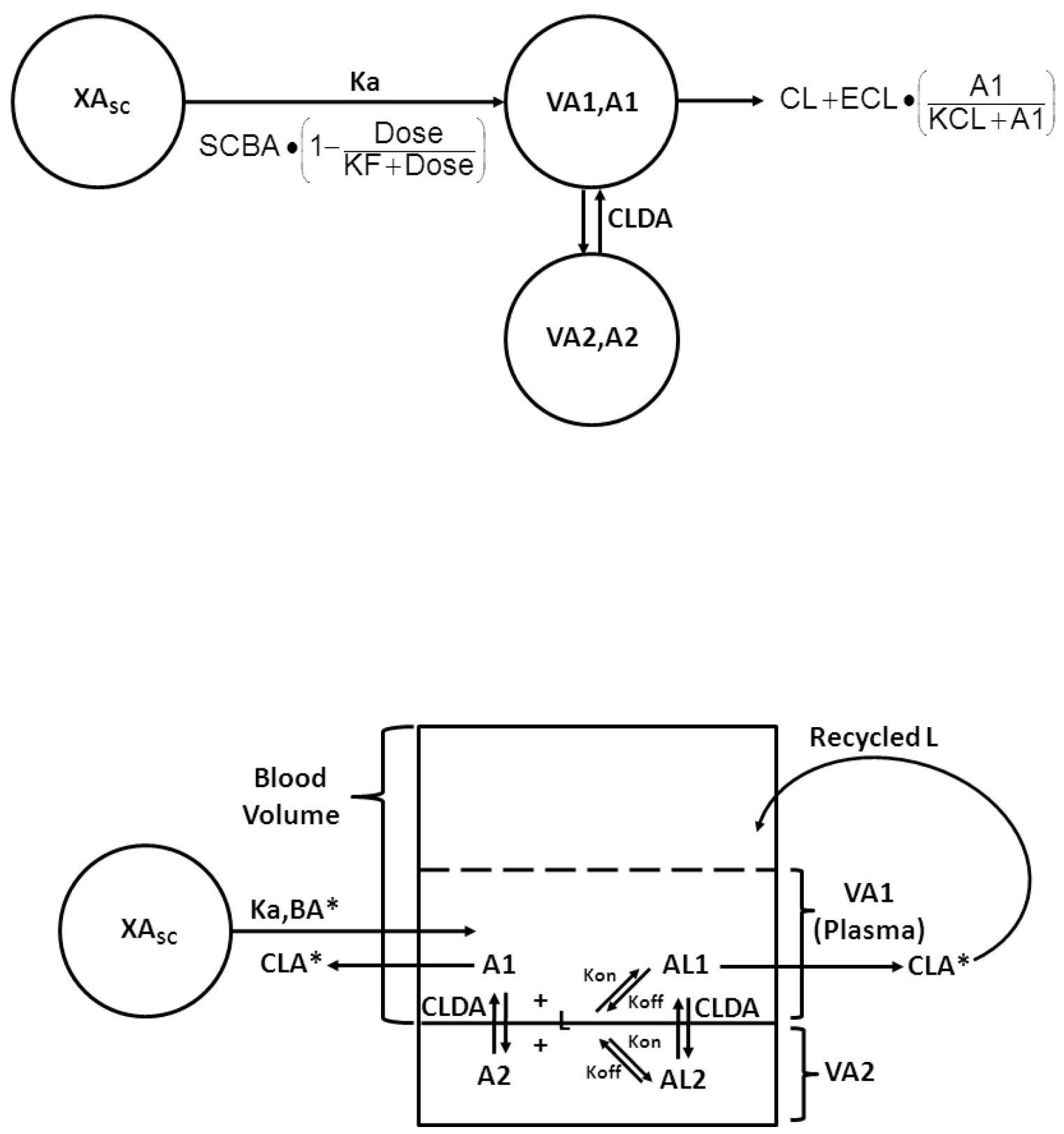

Figure 1. Model 1

(A) Display of a schematic diagram of the whole body topotecan PBPK model in mice, used as a part of the model 1 . All the tissues are represented by a rectangular compartment and are connected in an anatomical manner with blood flow represented by solid lines. The arrows represent the direction of the flow and the dashed line in the testes and kidney compartments represents separation between vascular and extra vascular sub-compartments. For the detail description of symbols and model structure please refer to Shah and Balthasar [16]. (B) Schematic representation of the two compartmental mammillary model used as a part of model 1 to characterize the pharmacokinetics of $8 \mathrm{C} 2$. The model incorporates dose dependent bioavailability from subcutaneous site and concentration dependent clearance 
from central compartment. $X A_{S C}$ represents amount of antibody available at the subcutaneous drug administration site. For details description of other symbols and model equations please refer to the theoretical section of this report. (C) Schematic diagram of the merged component of the model 1 , which involves blood compartment from topotecan PBPK model and the two compartments from the 8C2 mammillary model.

$\mathrm{BA}^{*}=\mathrm{SCBA} \bullet\left(1-\frac{\text { Dose }}{\mathrm{KF}+\text { Dose }}\right)$ andCLA ${ }^{*}=\mathrm{CL}+\mathrm{ECL} \bullet\left(\frac{\mathrm{A} 1}{\mathrm{KCL}+\mathrm{A} 1}\right)$. For details description of model symbols and equations please refer to the theoretical section of this report. 
A

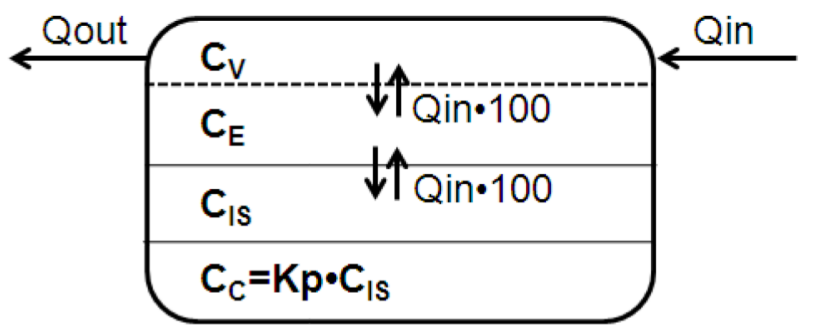

B
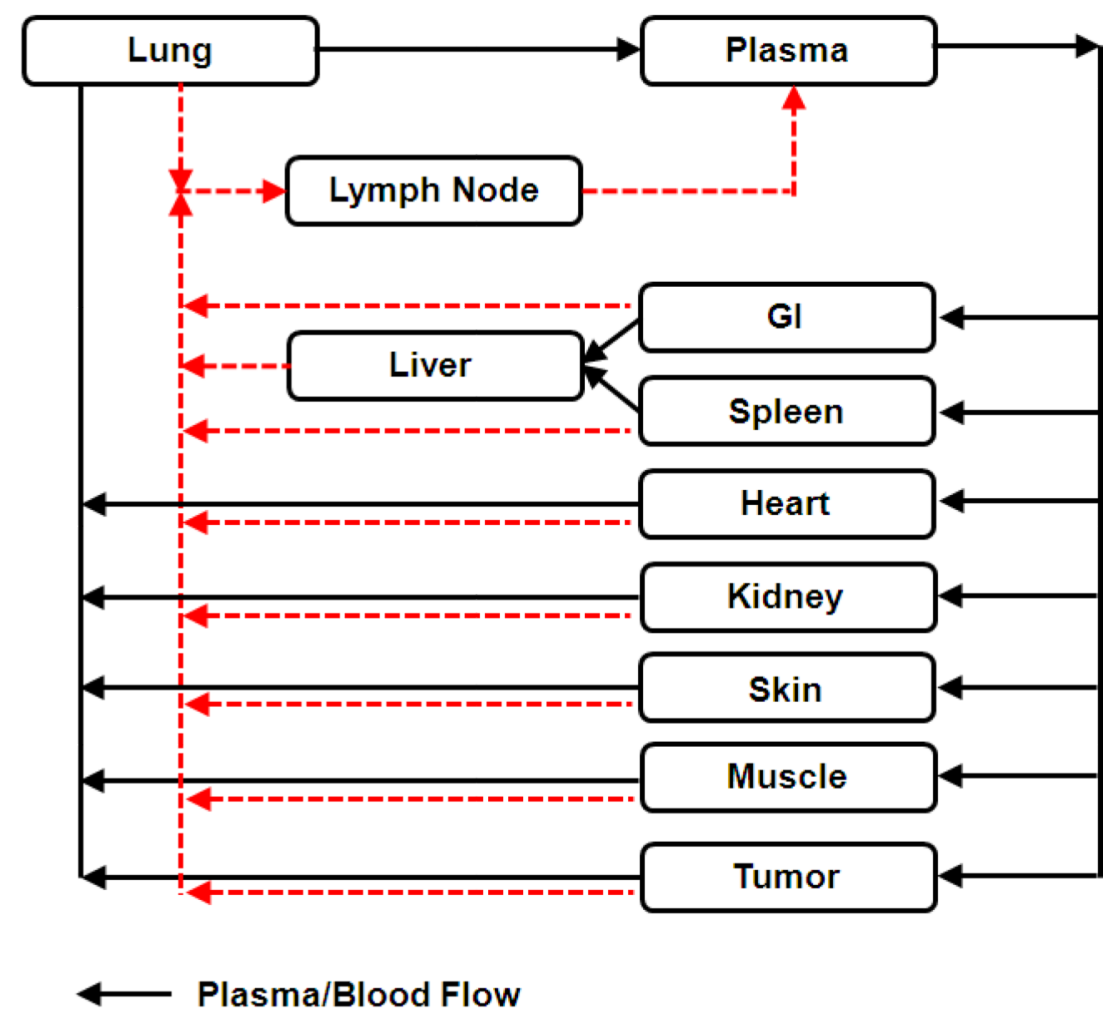

Lymph Flow 


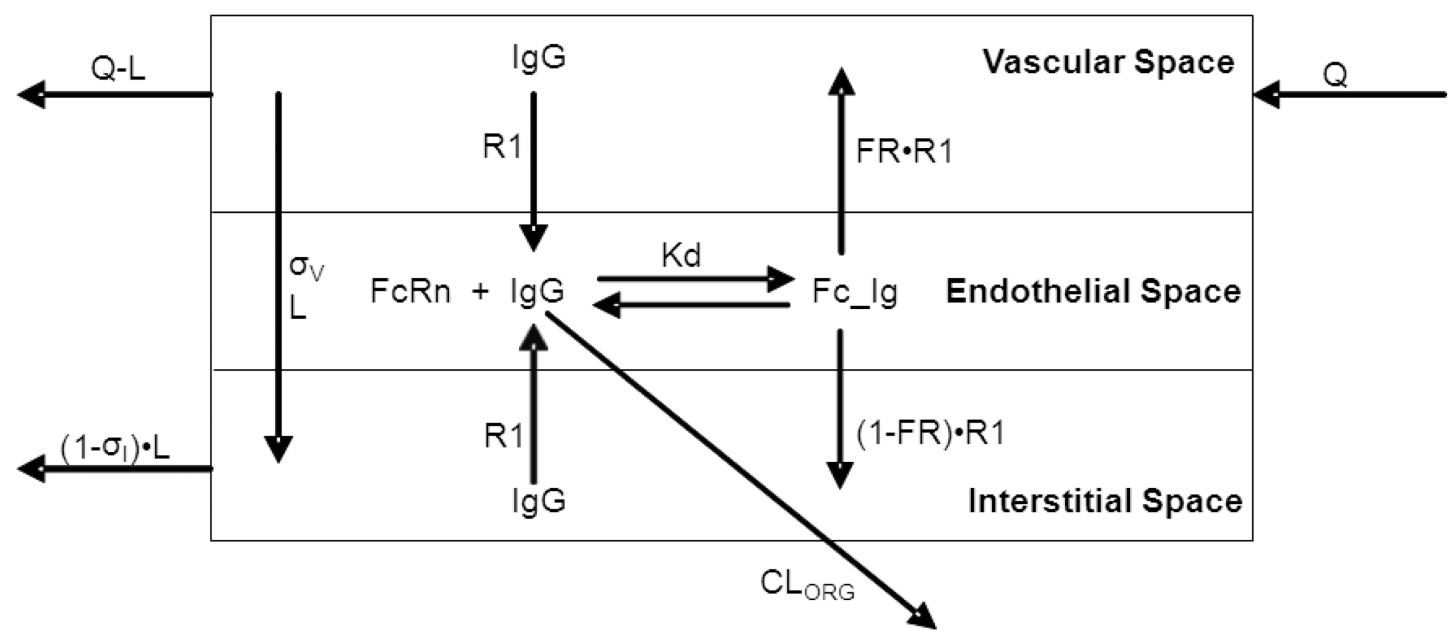

D

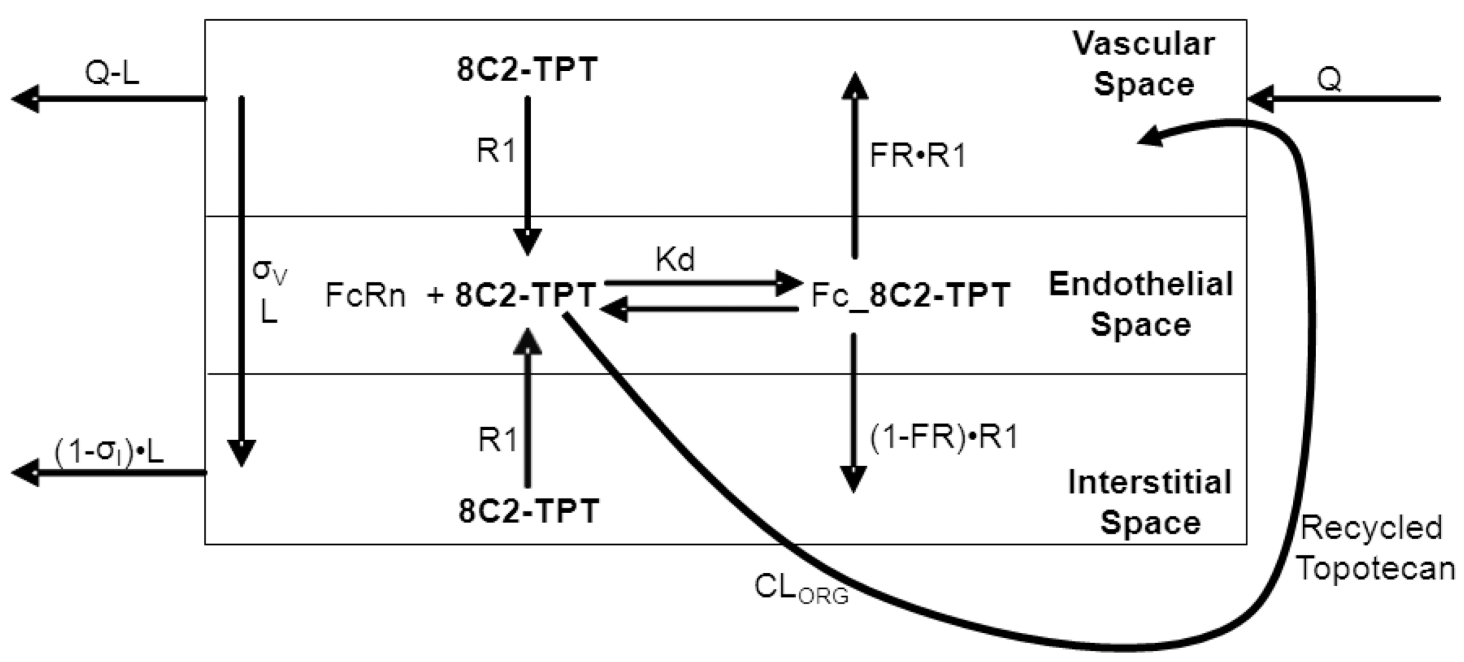

Figure 2. Model 2

(A) A representative non eliminating organ compartment of the modified topotecan PBPK model. Each organ compartment was divided in to 4 sub-compartments, vascular, endothelial, interstitial and cellular. $Q_{\text {in }}$ and $Q_{\text {out }}$ represent the blood flow coming in and going out of the organ. $C_{V}, C_{E}, C_{I S}$ and $C c$ refer to concentration of drug in vascular, endothelial, interstitial and cellular space. $K p$ is the partition coefficient of the drug in a particular tissue. The distribution clearance of drug between different sub-compartments was set to 100 times the value of blood flow to the organ. (B) Schematic diagram showing the PBPK model for 8C2 disposition used as a part of model 2. All major organs are represented 
by rectangular compartments that are connected in an anatomical fashion with plasma flow represented as solid lines and lymph flow represented as dashed lines. The arrows represent the direction of the flow. Each organ compartment is divided into sub-compartments as shown in figure 2C. For details description of the model please refer to Urva et al. [19]. (C) A representative tissue compartment from the $8 \mathrm{C} 2$ PBPK model. Each organ is divided into three sub-compartments representing a vascular space, endothelial space and an interstitial space. $Q$ and $L$ represent the plasma and lymph flow rates. $\sigma_{V}$ and $\sigma_{I}$ are the vascular and lymphatic reflection coefficients. $R I$ is the rate of uptake and return of $8 \mathrm{C} 2$ from the vascular and interstitial compartments into the endothelial compartment. $K d$ is the dissociation constant for antibody binding to $\mathrm{FcRn}$ that is present in the endothelial space of each organ. $F R$ represents the fraction of FcRn bound antibody that is recycled to the vascular space, and fu is the unbound fraction of antibody. $C L_{\text {organ }}$ is the clearance of unbound IgG from the endothelial compartment of each organ [19]. (D) A representative tissue compartment from the PBPK model used to characterize the disposition of topotecan- $8 \mathrm{C} 2$ complex. In general the model is similar to the model used to describe the disposition of $8 \mathrm{C} 2$ alone. In this model all of the topotecan that was eliminated as topotecan-8C2 complex was recycled back in the vascular compartment of each tissue. 
A
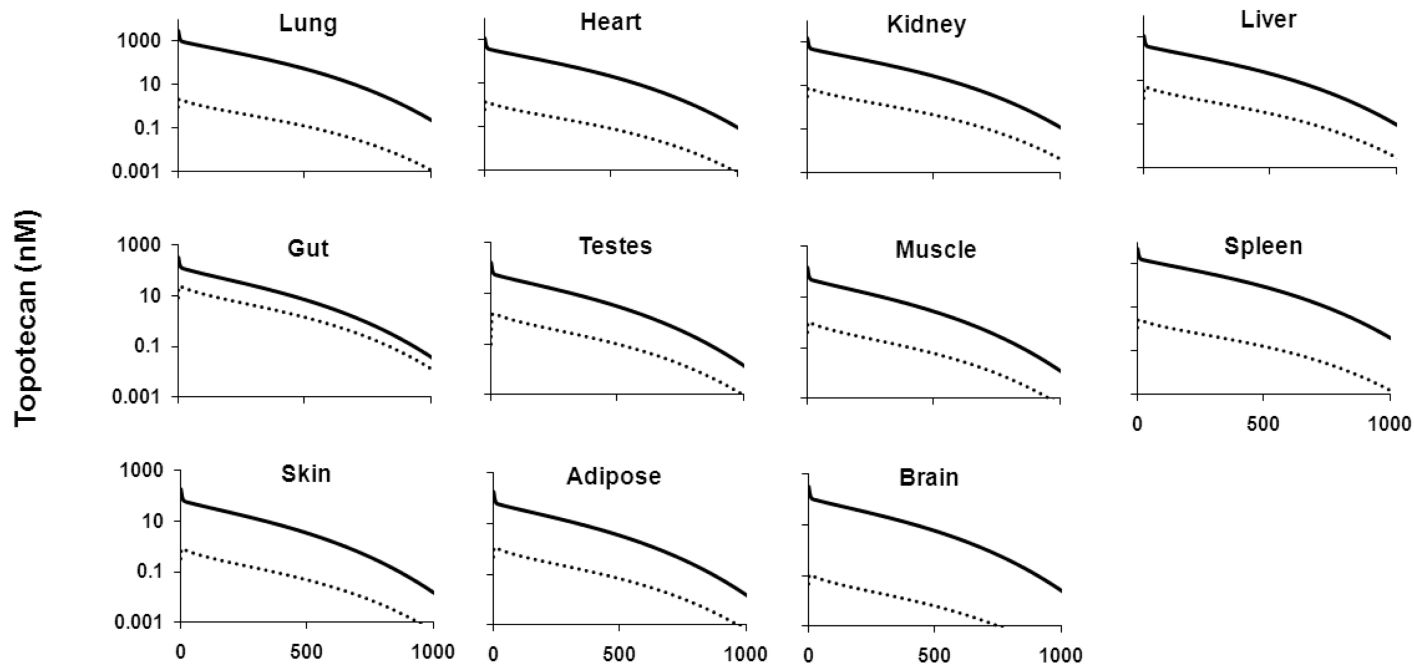

Time (h)

B

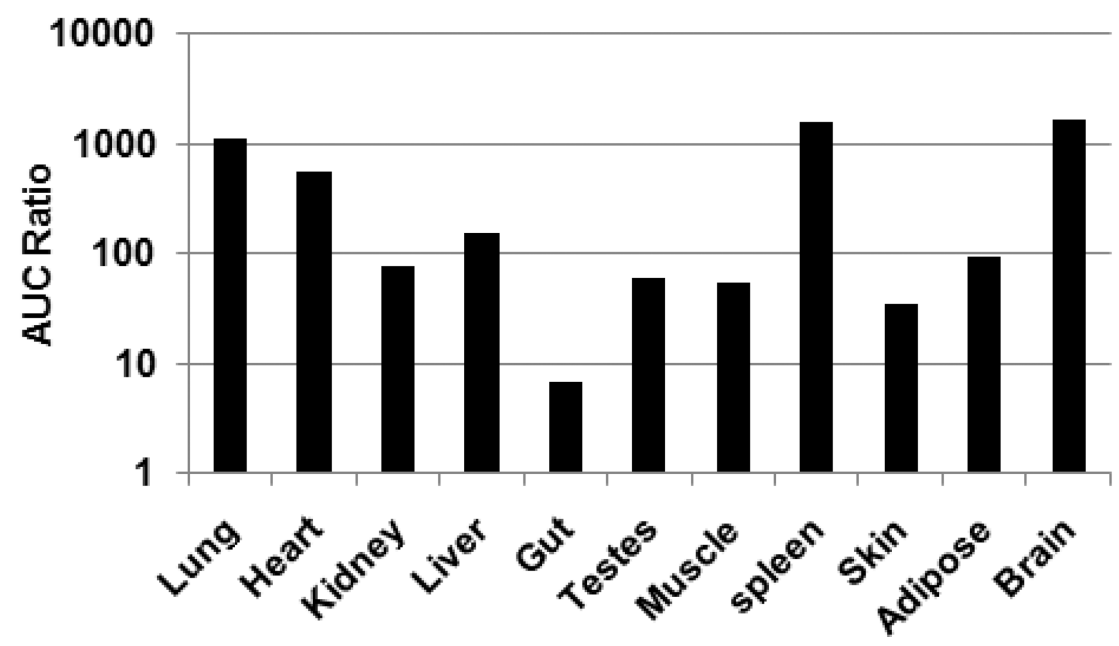

Figure 3. Effect of residual blood content on tissue topotecan concentrations

(A) The figure displays, for each tissue, two different profiles of topotecan concentrations vs. time simulated using model 1 . The dotted line represents the simulated tissue concentrations of topotecan that were driven by the free topotecan concentrations in the blood whereas the solid line represents the tissues concentrations that were generated by adding the amount of topotecan present is the residual blood to the simulated tissue concentrations of topotecan driven by the free blood concentrations. (B) The bar chart displays the AUC ratio for each tissue. The ratio was calculated by dividing AUCs calculated from the predicted concentration vs. time profiles, with or without consideration of the quantity of topotecan present in residual blood. 

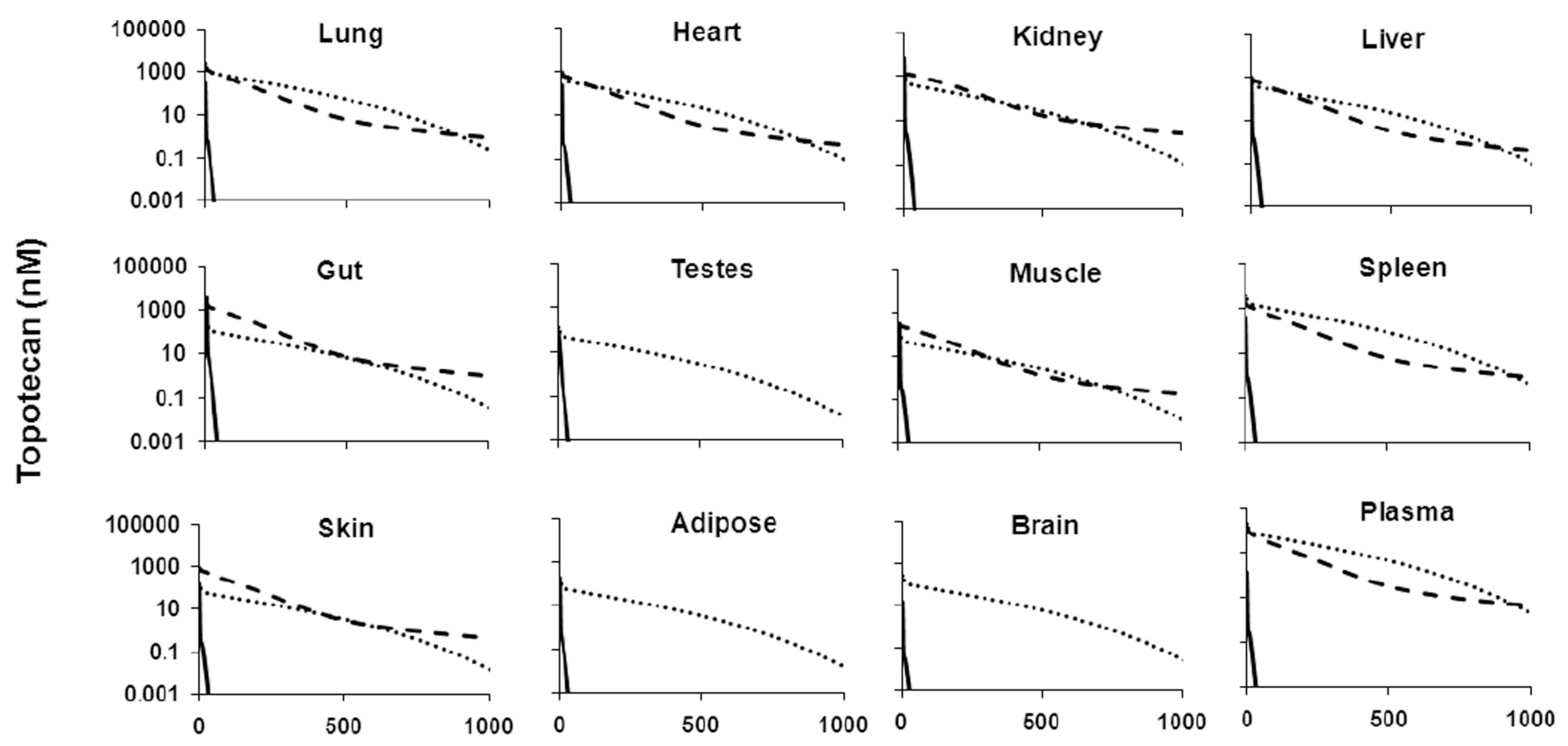

\section{Time (h)}

Figure 4. Comparison of model 1 and model 2

The figure displays, for each tissue, three different profiles. The solid line represents simulated topotecan concentrations after IP administration of $1 \mathrm{mg} / \mathrm{kg}$ topotecan alone. The dotted line represents the simulated topotecan concentrations after IP administration of 1 $\mathrm{mg} / \mathrm{kg}$ topotecan with IV co-administration of equimolar $8 \mathrm{C} 2$, generated using model 1 . And the dashed line represents the simulated topotecan concentrations after IP administration of $1 \mathrm{mg} / \mathrm{kg}$ topotecan with IV co-administration of equimolar $8 \mathrm{C} 2$, generated using model 2 . 

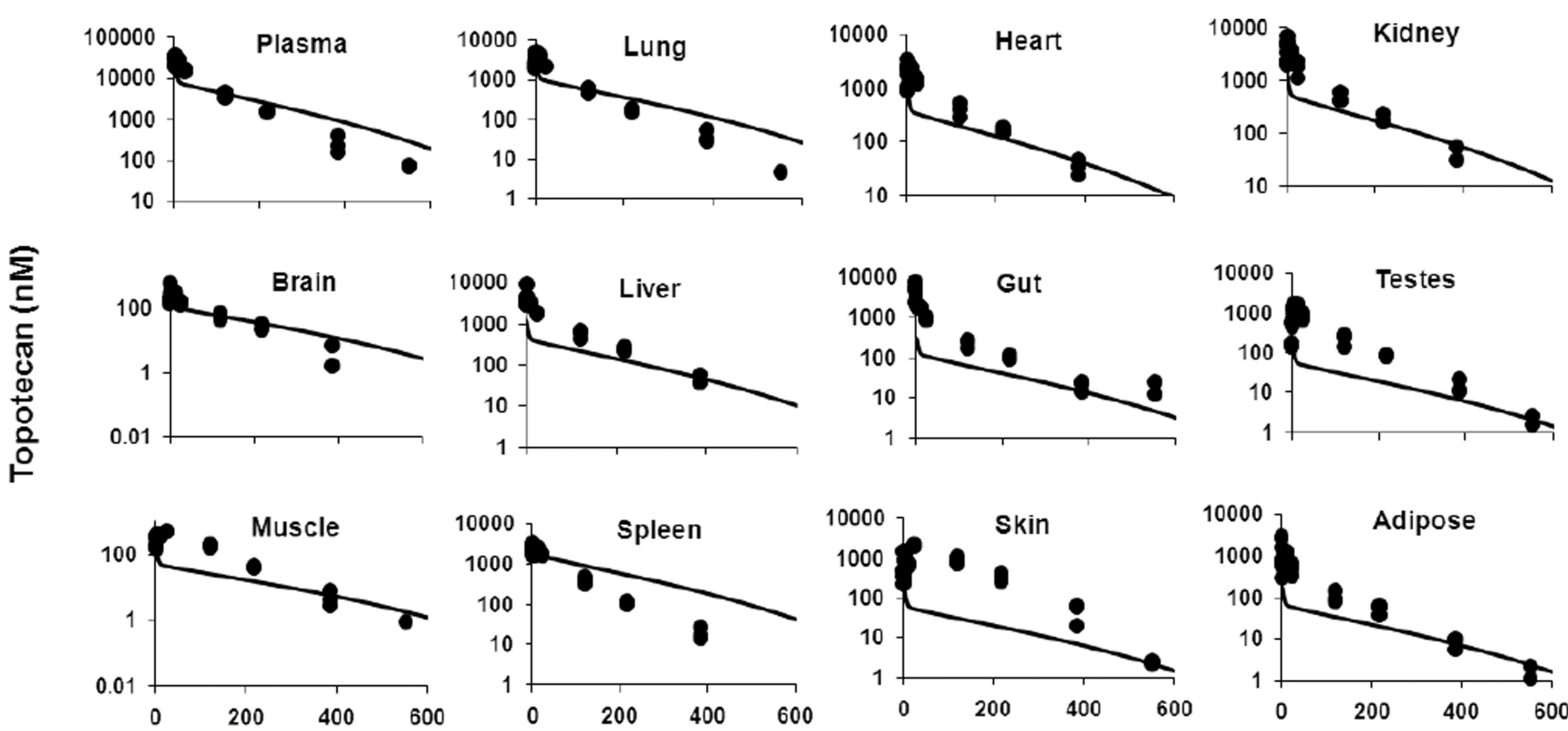

\section{Time (h)}

Figure 5. Evaluation of simulations results generated using model 1

The figure displays overlay of observed and model 1 simulated total topotecan concentrations for plasma and different tissues. The solid circles represent observed data points and the solid line represents simulated concentrations. Topotecan was administered IP at the dose of $1 \mathrm{mg} / \mathrm{kg}$ and 8C2 was administered IV at the dose of $164 \mathrm{mg} / \mathrm{kg}$. 

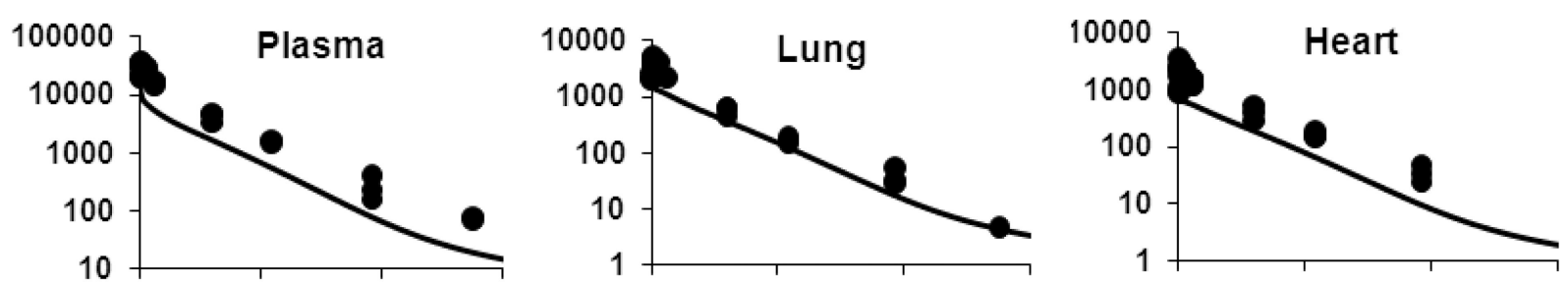

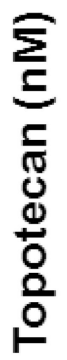
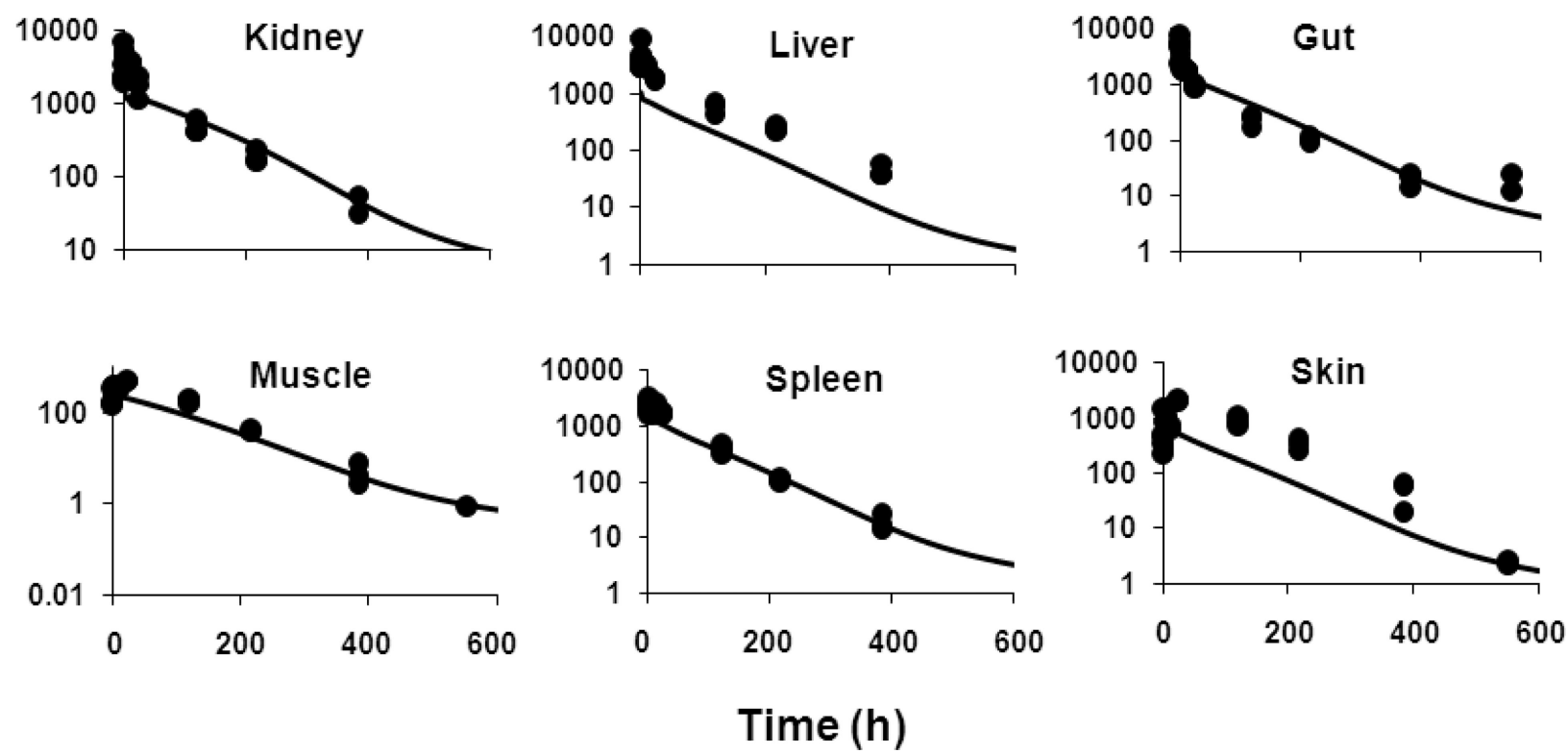

Figure 6. Evaluation of simulations results generated using model 2

The figure displays overlay of observed and model 2 simulated total topotecan concentrations for plasma and different tissues. The solid circles represent observed data points and the solid line represents simulated concentrations. Topotecan was administered IP at the dose of $1 \mathrm{mg} / \mathrm{kg}$ and $8 \mathrm{C} 2$ was administered IV at the dose of $164 \mathrm{mg} / \mathrm{kg}$. 
Table 1

Values of the parameters used for simulations using model 1.

\begin{tabular}{ccc}
\hline Parameter & Unit & Value \\
\hline VA2 & L & $3.07 \mathrm{E}-03$ \\
CL & L/h & $4.46 \mathrm{E}-06$ \\
CLD & L/h & $2.41 \mathrm{E}-04$ \\
Ka & $1 / h$ & 0.0207 \\
KF & nanomoles & 594 \\
KCL & $n M$ & $3.47 \mathrm{E}+04$ \\
VA1 & $\mathrm{L}$ & $9.90 \mathrm{E}-04$ \\
SCBA & & 1.00 \\
ECL & $\mathrm{L} / \mathrm{h}$ & $6.96 \mathrm{E}-05$ \\
Kon & $1 / n M / h$ & 9.27 \\
Koff & $1 / h$ & 4.68 \\
\hline
\end{tabular}


Table 2

Values of residual blood contents used for simulations using model 1.

\begin{tabular}{cc}
\hline Organ & \% Residual Blood \\
\hline Heart & 4.81 \\
Lung & 13.1 \\
Liver & 5.27 \\
Spleen & 21.5 \\
Muscle & 0.63 \\
Skin & 0.77 \\
Gut & 1.27 \\
Kidney & 6.23 \\
Brain & 1.35 \\
Adipose & 0.8 \\
Testis & 0.73 \\
\hline
\end{tabular}

The values were obtained from references: [20-22] 
Table 3

Parameter values for the modified topotecan PBPK model used for simulations using model 2.

\begin{tabular}{|c|c|c|}
\hline Parameter & Unit & Value \\
\hline $\mathrm{CLD}_{\mathrm{IP}}$ & $\mathrm{L} / \mathrm{h}$ & $1.08 \mathrm{E}-03$ \\
\hline $\mathrm{Vm}_{\mathrm{Ki}}$ & nanomoles/h & 2.63 \\
\hline $\mathrm{Km}_{\mathrm{Ki}}$ & $\mathrm{nM}$ & 0.223 \\
\hline $\mathrm{Vm}_{\mathrm{Li}}$ & nanomoles/h & 237 \\
\hline $\mathrm{Km}_{\mathrm{Li}}$ & $\mathrm{nM}$ & 730 \\
\hline Tau & $\mathrm{h}$ & 4.39 \\
\hline $\mathrm{PS}_{\mathrm{Te}}$ & $\mathrm{L} / \mathrm{h}$ & $7.71 \mathrm{E}-05$ \\
\hline$C L D_{\mathrm{Ki}}$ & $\mathrm{L} / \mathrm{h}$ & 271 \\
\hline $\mathrm{K} 1_{\mathrm{KpLi}}$ & $\mathrm{nM}$ & $3.41 \mathrm{E}+06$ \\
\hline $\mathrm{K} 2_{\mathrm{KdLi}}$ & $\mathrm{nM}$ & $2.33 \mathrm{E}+05$ \\
\hline $\mathrm{K}_{\mathrm{F}}$ & nanomoles & 275 \\
\hline $\mathrm{Vm} 2_{\mathrm{Ki}}$ & nanomoles $/ \mathrm{h}$ & $1.68 \mathrm{E}+06$ \\
\hline $\mathrm{Km} 2_{\mathrm{Ki}}$ & $\mathrm{nM}$ & $1.61 \mathrm{E}+05$ \\
\hline $\mathrm{K} 1_{\mathrm{KpKi}}$ & $\mathrm{nM}$ & $2.58 \mathrm{E}+06$ \\
\hline $\mathrm{K} 2_{\mathrm{KdKi}}$ & $\mathrm{nM}$ & $2.42 \mathrm{E}+05$ \\
\hline $\mathrm{K} 1_{\mathrm{KpGu}}$ & $\mathrm{nM}$ & $3.56 \mathrm{E}+05$ \\
\hline $\mathrm{K} 2_{\mathrm{KdGu}}$ & $\mathrm{nM}$ & 1971 \\
\hline
\end{tabular}




\section{Table 4}

Comparison of median \%PE values obtained for Model-1 and Model-2. The values were calculated by comparing observed data with model simulated values.

\begin{tabular}{|l|c|c|}
\hline Tissue & \multicolumn{2}{|c|}{ Median \%PE } \\
\cline { 2 - 3 } & Model-1 & Model-2 \\
\hline Total Plasma & 60.4 & 67.7 \\
Lung & 58.7 & 54.4 \\
Heart & 65.1 & 68.4 \\
Kidney & 73.1 & 66.6 \\
Liver & 74.4 & 74.6 \\
Gut & 88.2 & 46.0 \\
Testes & 81.2 & \\
Muscle & 80.7 & 39.8 \\
Spleen & 80.6 & 34.0 \\
Skin & 90.6 & 75.8 \\
Adipose & 78.5 & \\
Brain & 43.3 & \\
\hline
\end{tabular}

